
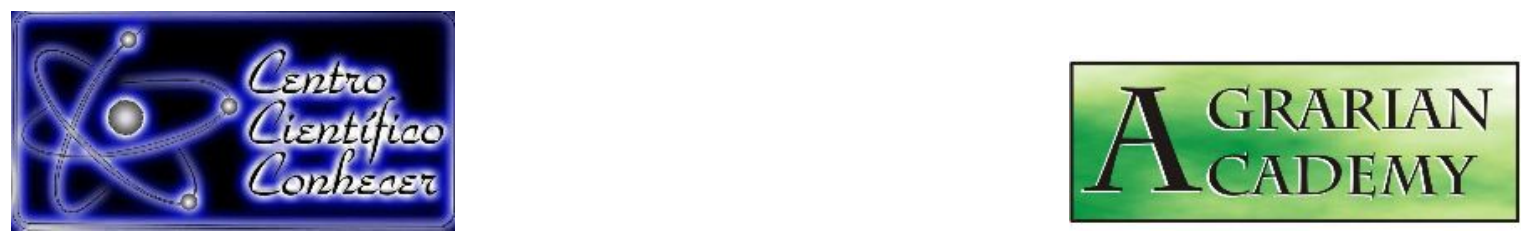

\title{
COMPORTAMENTO DA PRODUÇÃO E DOS PREÇOS DE OVOS DE GALINHA NO ESTADO DO PARÁ, BRASIL
}

\author{
Leonam do Nascimento Silva ${ }^{1}$; Marcos Antônio Souza dos Santos ${ }^{2}$; Fabrício \\ Khoury Rebello²; Andréia Santana Bezerra ${ }^{3}$; Cyntia Meireles Martins ${ }^{2}$ \\ ${ }^{1}$ Zootecnista, Universidade Federal Rural da Amazônia(UFRA), Belém, PA, \\ Brasil. \\ ${ }^{2}$ Professores Doutores, Universidade Federal Rural da Amazônia (UFRA), \\ (marcos.santos@ufra.edu.br) Belém/PA - Brasil. \\ ${ }^{3}$ Doutoranda em Ciência Animal, Universidade Federal do Pará (UFPA), \\ Castanhal, PA, Brasil.
}

Recebido em: 02/06/2019 - Aprovado em: 15/06/2019 - Publicado em: 22/07/2019 DOI: 10.18677/Agrarian_Academy_2019a11

\begin{abstract}
RESUMO
Este trabalho avaliou o comportamento da produção e dos preços de ovos de galinha no estado do Pará, durante 20 anos. Foram utilizadas séries temporais de produção e preços no período de 1995-2017. Efetuou-se a correção dos preços para eliminar o efeito inflacionário. O estado do Pará é o segundo maior produtor de ovos da região Norte do Brasil, representando $24,34 \%$, o primeiro é o estado do Amazonas (33,18\%), seguido por Tocantins (19,04\%) e Rondônia (15,99 \%). Observa-se que as microrregiões de Castanhal, Paragominas, Santarém e Belém concentraram mais de $80 \%$ da produção estadual, configurando-se como importantes zonas produtoras de ovos de galinhas. Entre 1995 e 1999 houve uma queda no preço dos ovos e o ano de 1999 foi o que apresentou o menor preço recebido pelos avicultores. Conclui-se que os preços exibiram instabilidade no período analisado, com ligeira tendência de crescimento de 1999 a 2009, flutuações mais acentuadas entre 2009 e 2012, e tendência de queda a partir de 2013.
\end{abstract}

PALAVRAS-CHAVE: Avicultura de Postura, Agronegócio, Mercado Agropecuário.

\section{BEHAVIOR OF PRODUCTION AND THE PRICE OF CHICKEN EGGS IN THE STATE OF PARÁ}

\section{ABSTRACT}

This work evaluates the behavior of chicken egg production and prices in the Pará state for 20 years. Time series of production and prices were used in the period 1995-2017. Price correction was done to eliminate the inflationary effect. Pará state is the second largest egg producer in the northern region of Brazil, accounting for $24.34 \%$, where the former is the state of Amazonas (33.18\%), followed by Tocantins 
(19.04\%) and Rondônia (15.99\%). Castanhal, Paragominas, Santarém and Belém concentrated more than $80 \%$ of the state production, being configured as important zones producing eggs of hens. Between 1995 and 1999 there was a decrease in the price of eggs and 1999 was the one that presented the lowest price received by poultry farmers. It can be concluded that prices showed instability in the analyzed period, with a slight growth trend from 1999 to 2009, more pronounced fluctuations between 2009 and 2012, and a downward trend from 2013 onwards.

KEYWORDS: Poultry farming, Agribusiness, Agricultural Market.

\section{INTRODUÇÃO}

O ovo é um alimento importante para a segurança alimentar das populações humanas, em função disso a avicultura tem sido uma das atividades zootécnicas que mais tem recebido investimentos em ciência e tecnologia, visando ampliar a oferta desse produto nos mercados (CARNEIRO, 2012; GUYONNET, 2012).

A produção de ovos é realizada com duas finalidades básicas: a incubação, visando à reprodução das aves de postura e corte; e o consumo, a partir da produção de ovos de mesa, destinados ao consumo direto ou indireto. Isto estimulou diversos investimentos na atividade, nos últimos anos, visando dotá-la, principalmente, em termos de infraestrutura e equipamentos para os sistemas de criação (MARTINS, 2002; CARNEIRO, 2012).

O Brasil é responsável por $3 \%$ da produção mundial de ovos, ocupando a $5^{\mathrm{a}}$ posição no ranking internacional. A produção brasileira de ovos de galinha totalizou 44 milhões de dúzias de ovos em 2014 (FAO, 2016). De acordo com o IBGE (2017) a região Sudeste é a maior produtora $(43,5 \%)$, estando à frente do Sul $(24,3 \%)$, Nordeste $(16,8 \%)$, Centro-Oeste $(11,8)$ e Norte $(3,6 \%)$. Na região Norte, o estado que apresenta o maior índice de produção avícola é o Amazonas, seguido pelo estado do Pará. O estado do Pará é o 16ํㅡ no ranking da produção nacional. O Estado responde por apenas $1 \%$ da produção nacional, no qual São Paulo é responsável por $40 \%$, seguido pelo Paraná (11\%), Minas Gerais e Rio Grande do Sul ( $8,5 \%$ cada um), Pernambuco (6\%), Ceará $(4,5 \%)$ e Goiás $(3,7 \%)$.

O objetivo deste trabalho foi avaliar o comportamento da produção e do preço de ovos de galinha entre os anos de 1995 a 2017 no estado do Pará. Esse tipo de análise é importante para os agentes envolvidos na cadeia produtiva de ovos e, também, para as instituições de pesquisa, extensão e fomento, pois disponibilizam informações estratégicas para formulação de políticas de fomento à atividade e ao desenvolvimento rural.

\section{MATERIAL E MÉTODOS}

O trabalho foi desenvolvido a partir de dados da Organização das Nações Unidas para a Alimentação e Agricultura (FAO), tendo como fonte as informações da produção mundial de ovos de galinha, usando a unidade da produção de 1.000 dúzias, dos anos de 2000, 2010 e 2014. Foi efetuado o cálculo para mensurar o percentual da produção do país em relação ao total produzido no mundo.

Também foram utilizadas séries temporais de produção e valor da produção de ovos de galinha, no período de 1995 a 2017, obtida no site do Instituto Brasileiro de Geografia e Estatística (IBGE, 2017). Utilizou-se como base a Pesquisa Pecuária Municipal (PPM) que possui informações sobre o efetivo das espécies animais e dos produtos da pecuária, tendo como unidade de coleta os municípios. Por conseguinte, utilizaram-se os dados da produção estadual e das microrregiões 
paraenses para elaboração das tabelas e gráficos.

Adicionalmente, utilizaram-se os dados do levantamento trimestral da Produção de Ovos de Galinha, envolvendo o número de informantes, número de galinhas poedeiras, quantidade de ovos produzidos entre 2006-2017. Também foi realizado o cálculo da produtividade com base nestes dados. Esse levantamento produz indicadores sobre a produção física de ovos de galinha, tendo como unidade de coleta as granjas avícolas que possuem 10.000 ou mais bicos de galinhas poedeiras.

Efetuou-se a correção dos preços para eliminar o efeito inflacionário, por meio do Índice Geral de Preços Disponibilidade Interna (IGP-DI) da Fundação Getúlio Vargas (FGV), com base em julho de 2017 (FGV, 2017).

\section{RESULTADOS E DISCUSSÃO}

\section{PRODUÇÃO MUNDIAL}

O desenvolvimento econômico e o aumento da urbanização têm ampliado a demanda por ovos para consumo. Isto abriu caminho para maiores oportunidades no mercado às empresas de criação de aves destinadas a produção de ovos. No passado, a maior parte da produção de ovos vinha de pequenas propriedades em que se criavam galinhas caipiras. Mas a melhoria da tecnologia e o desenvolvimento de equipamentos sofisticados propiciou uma especialização dos produtores, visando criações com finalidade comercial em maior escala (BUENO ; GHOBRIL, 2017).

Segundo dados da FAO (2018), entre os anos de 2000 e 2016, a produção mundial de ovos aumentou $31,97 \%$, passando de 966,5 bilhões de dúzias de ovos para 1,4 trilhões de dúzias. A China respondeu por $38,70 \%$ de produção global, impulsionado pelo vigoroso crescimento do setor avícola nos últimos 20 anos, ocupando, isoladamente, o primeiro lugar na produção mundial. Atualmente, a China exporta ovos para muitos países na Ásia, África, Europa, América do Norte e Oceania.

Os Estados Unidos participaram com 7,35\% da produção mundial com 101,9 bilhão de dúzias de ovos produzidos anualmente. A maioria da produção é para consumo humano. Há aproximadamente 186 empresas produtoras de ovos com grupos de 75.000 galinhas ou mais, e os Estados Unidos ocupa a segunda posição no ranking. A Índia, terceira posição no ranking mundial, responde por 5,98\% da produção. A produção da Índia foi de 82,9 bilhões de dúzias de ovos, em 2016, a quarta posição é ocupada pelo México (54,4 bilhões de dúzias de ovos) (FAO, 2018).

O Brasil, com $3,3 \%$ da produção, ocupa a $5^{\text {a }}$ posição no ranking mundial de produção de ovos. A produção totalizou 45,8 bilhões de dúzias, em 2016, um incremento de $51,67 \%$ quando comparado com o ano de 2000 (30,2 bilhões) (FAO, 2018).

A Rússia e o Japão apresentaram produções próximas a do Brasil, respondendo, respectivamente, pela sexta e sétima posição no ranking. A Indonésia $(2,40 \%)$, Turquia $(1,31 \%)$ e Ucrânia $(1,07 \%)$ vêm na sequência dos maiores produtores mundiais (Tabela 1) (FAO, 2018). 
TABELA 1 - Produção mundial de ovos, 2000, 2010, 2014 e 2016.

\begin{tabular}{lllllllll}
\hline & \multicolumn{2}{c}{$\mathbf{2 0 0 0}$} & \multicolumn{2}{c}{$\mathbf{2 0 1 0}$} & \multicolumn{2}{c}{$\mathbf{2 0 1 4}$} & \multicolumn{2}{c}{$\mathbf{2 0 1 6}$} \\
\cline { 2 - 9 } Países & $\begin{array}{l}\text { Produção } \\
(\mathbf{1 0 0 0} \mathbf{d z} .)\end{array}$ & $\mathbf{( \% )}$ & $\begin{array}{l}\text { Produção } \\
(\mathbf{1 0 0 0} \mathbf{d z} .)\end{array}$ & $\mathbf{( \% )}$ & $\begin{array}{l}\text { Produção } \\
(\mathbf{1 0 0 0} \mathbf{d z} .)\end{array}$ & (\%) & $\begin{array}{l}\text { Produção } \\
(\mathbf{1 0 0 0} \mathbf{d z} .)\end{array}$ & (\%) \\
\hline China & 378.238 & 39,13 & 476.402 & 39,28 & 459.063 & 35,99 & 536.710 & 38,70 \\
EUA & 84.402 & 8,73 & 91.482 & 7,54 & 100.879 & 7,91 & 101.952 & 7,35 \\
Índia & 36.632 & 3,79 & 61.420 & 5,06 & 75.970 & 5,96 & 82.929 & 5,98 \\
México & 35.758 & 3,70 & 47.622 & 3,93 & 51.343 & 4,03 & 54.403 & 3,92 \\
Brasil & 30.189 & 3,12 & 38.960 & 3,21 & 44.811 & 3,51 & 45.789 & 3,30 \\
Rússia & 33.910 & 3,51 & 40.392 & 3,33 & 41.313 & 3,24 & 43.086 & 3,11 \\
Japão & 42.257 & 4,37 & 41.900 & 3,45 & 41.698 & 3,27 & 42.704 & 3,08 \\
Indonésia & 14.266 & 1,48 & 24.911 & 2,05 & 28.872 & 2,26 & 33.214 & 2,40 \\
Turquia & 13.508 & 1,40 & 11.840 & 0,98 & 17.145 & 1,34 & 18.097 & 1,31 \\
Ucrânia & 8.674 & 0,90 & 16.864 & 1,39 & 19.391 & 1,52 & 14.798 & 1,07 \\
Outros & 288.678 & 29,87 & 361.138 & 29,77 & 395.018 & 30,97 & 413.015 & 29,78 \\
\hline Mundo & $\mathbf{9 6 6 . 5 1 6}$ & $\mathbf{1 0 0 , 0 0}$ & $\mathbf{1 . 2 1 2 . 9 3 5}$ & $\mathbf{1 0 0 , 0 0}$ & $\mathbf{1 . 2 7 5 . 5 0 6}$ & $\mathbf{1 0 0 , 0 0}$ & $\mathbf{1 . 3 8 6 . 6 9 7}$ & $\mathbf{1 0 0 , 0 0}$ \\
\hline
\end{tabular}

Fonte: Elaborado a partir de dados da FAO, (2018).

\section{PRODUÇÃO NO BRASIL}

Segundo dados do IBGE (2018), a produção brasileira de ovos de galinha alcançou 4,2 milhões de dúzias. A região Sudeste foi a maior produtora $(44,76 \%)$, estando à frente do Sul $(24,07 \%)$, Nordeste $(16,10 \%)$, Centro-Oeste $(11,54 \%)$ e Norte (3,54 \%). No entanto, comparando o ano de 2017 em relação a 2000, a região Norte contou com o maior incremento na produção de ovos (122,7\%), seguida das regiões Sudeste $(56,12 \%)$, Nordeste $(50,54 \%)$ e Sul $(41,98 \%)$, sendo a região Centro-Oeste a única a demonstrar decréscimo na produção da ordem de $-36,03 \%$. Isto demonstra que apesar da região Sudeste ser detentora da maior produção nacional, alguns estados de outras regiões estão ganhando espaço nessa atividade.

No ano de 2017, São Paulo foi o estado com a maior produção de ovos de galinha, participando com $26,4 \%$ do total nacional, seguido por Paraná $(9,6 \%)$ e Minas Gerais (9,3\%). O Espírito Santo figurou na quarta posição $(8,81 \%)$, acompanhado logo a seguir pelo Rio Grande do Sul (8,4\%). O estado do Amapá ocupa a última posição do ranking nacional (IBGE, 2018).

O município que mais produz ovos no Brasil, também conhecido como "capital do ovo", é Bastos (SP). Na sequência identificam-se os municípios de Santa Maria de Jetibá (ES), primavera do Leste (MT) e Itanhandu (MG) (IBGE, 2018).

TABELA 2 - Produção de ovos no Brasil, 1995, 2000, 2010 e 2017.

\begin{tabular}{lllllllll}
\hline Estados & $\mathbf{1 9 9 5}$ & $\%$ & $\mathbf{2 0 0 0}$ & $\%$ & $\mathbf{2 0 1 0}$ & $\%$ & $\mathbf{2 0 1 7}$ & $\%$ \\
\hline SP & 717.711 & 30,43 & 799.215 & 31,76 & 867.652 & 26,72 & 1.120 .516 & 26,39 \\
PR & 247.781 & 10,50 & 286.954 & 11,41 & 335.441 & 10,33 & 406.313 & 9,57 \\
MG & 255.329 & 10,82 & 289.181 & 11,49 & 375.084 & 11,55 & 394.554 & 9,29 \\
ES & 39.955 & 1,69 & 63.736 & 2,53 & 178.280 & 5,49 & 373.998 & 8,81 \\
RS & 249.946 & 10,60 & 260.350 & 10,35 & 300.728 & 9,26 & 354.888 & 8,36 \\
SC & 116.169 & 4,92 & 136.059 & 5,41 & 209.582 & 6,46 & 260.784 & 6,14 \\
PE & 195.664 & 8,29 & 118.198 & 4,70 & 147.881 & 4,55 & 240.319 & 5,66 \\
GO & 92.228 & 3,91 & 110.504 & 4,39 & 172.573 & 5,32 & 222.748 & 5,25 \\
MT & 10.782 & 0,46 & 37.587 & 1,49 & 122.679 & 3,78 & 196.113 & 4,62 \\
\hline
\end{tabular}




\begin{tabular}{lllllllll}
\hline CE & 102.450 & 4,34 & 88.100 & 3,50 & 125.176 & 3,85 & 177.766 & 4,19 \\
BA & 56.229 & 2,38 & 70.174 & 2,79 & 87.713 & 2,70 & 84.649 & 1,99 \\
AM & 6.896 & 0,29 & 17.697 & 0,70 & 67.017 & 2,06 & 49.856 & 1,17 \\
RN & 17.262 & 0,73 & 23.912 & 0,95 & 31.447 & 0,97 & 49.295 & 1,16 \\
MS & 24.307 & 1,03 & 25.589 & 1,02 & 40.184 & 1,24 & 47.075 & 1,11 \\
PB & 30.694 & 1,30 & 32.848 & 1,31 & 27.997 & 0,86 & 37.911 & 0,89 \\
PA & 32.849 & 1,39 & 24.559 & 0,98 & 24.404 & 0,75 & 36.564 & 0,86 \\
AL & 13.791 & 0,58 & 18.399 & 0,73 & 27.250 & 0,84 & 31.674 & 0,75 \\
TO & 10.355 & 0,44 & 6.213 & 0,25 & 8.405 & 0,26 & 28.601 & 0,67 \\
SE & 6.719 & 0,28 & 7.578 & 0,30 & 26.507 & 0,82 & 24433 & 0,57 \\
RO & 11.973 & 0,51 & 7.104 & 0,28 & 9.467 & 0,29 & 24031 & 0,57 \\
DF & 37.148 & 1,57 & 38.510 & 1,53 & 16.871 & 0,52 & 23763 & 0,56 \\
PI & 24.025 & 1,02 & 16.184 & 0,64 & 14.599 & 0,45 & 22.505 & 0,53 \\
MA & 22.706 & 0,96 & 16.022 & 0,64 & 9.333 & 0,29 & 14.748 & 0,35 \\
RJ & 30.557 & 1,30 & 16.719 & 0,67 & 12.899 & 0,40 & 10.979 & 0,26 \\
AC & 3.374 & 0,14 & 1.960 & 0,08 & 2.767 & 0,09 & 5.744 & 0,14 \\
RR & 1.863 & 0,08 & 2.424 & 0,10 & 4.731 & 0,15 & 5.392 & 0,13 \\
AP & 161 & 0,01 & - & - & 53 & 0,00 & 64 & 0,00 \\
\hline Brasil & $\mathbf{2 . 3 5 8 . 9 2 3}$ & $\mathbf{1 0 0 , 0 0}$ & $\mathbf{2 . 5 1 5 . 7 7 3}$ & $\mathbf{1 0 0 , 0 0}$ & $\mathbf{3 . 2 4 6 . 7 1 9}$ & $\mathbf{1 0 0 , 0 0}$ & $\mathbf{4 . 2 4 5 . 2 8 4}$ & $\mathbf{1 0 0 , 0 0}$ \\
\hline
\end{tabular}

Fonte: Elaborado a partir de dados do IBGE, 2018.

\section{PRODUÇÃO NO ESTADO DO PARÁ}

No Estado do Pará, até o ano de 1960, a avicultura de corte e postura era uma atividade restrita aos quintais das pequenas propriedades rurais. Resumia-se a uma avicultura tradicional em que se criavam as chamadas galinhas "caipiras" de dupla aptidão: produção de carne e ovos, para autoconsumo e comercialização apenas do excedente (SANTOS et al., 2000).

A atividade passou a ganhar maior dinamismo a partir 1965, com uma iniciativa da Secretaria de Agricultura do Estado do Pará (SAGRI) que, por meio da formalização de convênio com o Ministério da Agricultura, permitiu a implantação de um incubatório com a capacidade para $22 \mathrm{mil}$ ovos/mês, no município de Ananindeua, Região Metropolitana de Belém, com objetivo de solucionar um dos principais fatores limitantes ao desenvolvimento da atividade avícola na época que era a oferta de pintos de um dia (SANTOS et al., 2000).

Em 2016 e 2017, o estado do Pará participou com 0,86\% da produção nacional. Cabe ressaltar que, em 1995, a participação do Estado foi maior com $1,39 \%$. Os dados da produção paraense de ovos indicam que mesmo com o crescimento de seus números em termos absolutos, sua participação percentual no total nacional é ligeiramente decrescente (Tabela 3), indicando perda de importância relativa. Os anos de 1995, 1998 e 1999 foram os que apresentaram a maior produção, e no ano de 1996 foi registrado o menor volume produzido. 
TABELA 3 - Quantidade de ovos produzidos (1.000 dúzias), no estado do Pará e no Brasil, 1995 a 2017.

\begin{tabular}{cccc}
\hline Ano & Brasil & Pará & Percentual (\%) \\
\hline 1995 & 2.358 .923 & 32.849 & 1,39 \\
1996 & 2.287 .622 & 12.442 & 0,54 \\
1997 & 2.444 .130 & 20.743 & 0,85 \\
1998 & 2.315 .900 & 32.323 & 1,40 \\
1999 & 2.444 .985 & 35.259 & 1,44 \\
2000 & 2.515 .773 & 24.559 & 0,98 \\
2001 & 2.565 .239 & 18.811 & 0,73 \\
2002 & 2.579 .561 & 21.456 & 0,83 \\
2003 & 2.618 .567 & 16.432 & 0,63 \\
2004 & 2.693 .220 & 15.464 & 0,57 \\
2005 & 2.773 .429 & 17.433 & 0,63 \\
2006 & 2.933 .901 & 22.387 & 0,76 \\
2007 & 2.965 .316 & 21.929 & 0,74 \\
2008 & 3.072 .708 & 22.992 & 0,75 \\
2009 & 3.187 .636 & 24.591 & 0,77 \\
2010 & 3.246 .719 & 24.404 & 0,75 \\
2011 & 3.394 .020 & 28.173 & 0,83 \\
2012 & 3.473 .021 & 26.862 & 0,77 \\
2013 & 3.614 .178 & 28.425 & 0,79 \\
2014 & 3.731 .796 & 29.029 & 0,78 \\
2015 & 3.769 .324 & 32.168 & 0,85 \\
2016 & 3.802 .943 & 32.596 & 0,86 \\
2017 & 4.245 .284 & 36.564 & 0,86 \\
\hline
\end{tabular}

Fonte: Elaborado a partir de dados do IBGE, (2018).

Apesar da pequena representatividade da produção de ovos paraense em termos de Brasil, estes números são significativos, no âmbito da região Norte, onde o estado do Pará responde por $24,33 \%$ do total, ocupando o segundo lugar. O primeiro estado produtor é o Amazonas $(33,18 \%)$, seguidos pelos estados de Tocantins (19,33\%) e Rondônia (15,99\%), conforme ilustrado na Figura 1 (IBGE, 2018).

Cabe o registro de que o estado do Pará detinha a liderança da produção de ovos na região até o ano de 2001. Em 2002 a produção amazonense foi 31\% maior que a paraense, e em 2015 foi quase o dobro (99,91\%). Segundo Cruz et al. (2016), a partir de 1990 foi estimulada a expansão e a profissionalização na cadeia produtiva da avicultura de postura amazonense, com mudança na mentalidade referente à gestão e o aprimoramento tecnológico, o que proporcionou à atividade atender entre 90 e $95 \%$ da demanda interna, mesmo com a deficiência na oferta de insumos básicos para a produção de ração. 


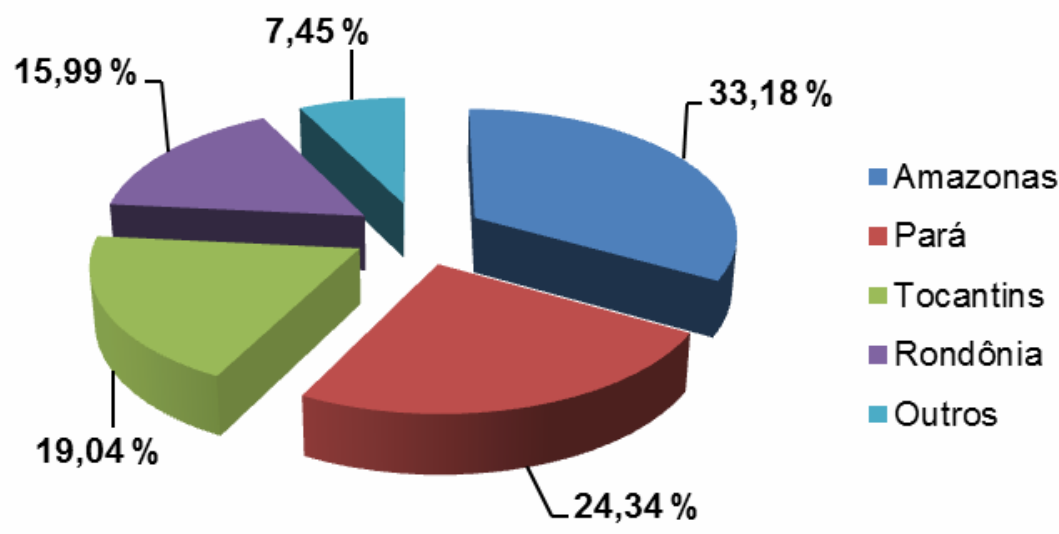

FIGURA 1 - Produção de ovos na Região Norte, 2017.

Fonte: Elaborado a partir de dados do IBGE, (2018).

De acordo com as pesquisas trimestrais de ovos de galinha do IBGE (2018), a produção total de ovos de galinha no Pará, no ano de 2017, foi de aproximadamente 26,11 mil dúzias, com 4,41 milhões de galinhas poedeiras alojadas. Observou-se que a produção de ovos e o número de galinhas poedeiras apresentaram taxas de crescimento de $8,4 \%$ e $7,5 \%$ ao ano, respectivamente, no período avaliado (2006 a 2017). Nesse período, o número de informantes não exibiu grandes variações, registrando-se uma estabilização durante os anos de 2009 a 2015 com aumento de um informante para os anos seguintes (Tabela 4). Este fato indica que a atividade não tem sido atrativa o suficiente para estimular novos produtores a se inserirem nessa cadeia produtiva.

A produtividade entre o período de 2006 a 2016 manteve-se estável, com taxa de crescimento de $0,8 \%$ ao ano. Nota-se que essa variável exibiu ligeira tendência de crescimento até o ano de 2012, sofrendo uma queda em 2013 e 2014. O Estado do Pará apresentou produtividade de 71,02 ovos/ave/ano, em 2017. De acordo com Bueno e Ghobril (2017), a produtividade no estado de São Paulo, o maior produtor nacional, foi da ordem de 258 ovos/ave/ano, isto representa 3,6 vezes o valor da produtividade obtida na avicultura de postura do Pará. Os autores justificam que esse desempenho é fruto da melhoria genética nas linhagens comerciais, além do manejo nutricional e ambiental. Em função da necessidade de investimentos em tecnologias para se atingir esse nível de produtividade, a permanência de produtores pouco especializados em muito limitada.

TABELA 4 - Número de informantes, Número de galinhas poedeiras, Quantidade de ovos produzidos e Produtividade, Estado do Pará, 2006 a 2017.

\begin{tabular}{ccccc}
\hline Ano & $\begin{array}{c}\mathbf{N}^{\circ} \text { de informantes } \\
\text { (Unidades) }\end{array}$ & $\begin{array}{c}\mathbf{N}^{\circ} \text { de galinhas } \\
\text { poedeiras (Cabeças) }\end{array}$ & $\begin{array}{c}\text { Quantidade de ovos } \\
\text { produzidos (Mil } \\
\text { dúzias) }\end{array}$ & $\begin{array}{c}\text { Produtividade } \\
\text { (ovos/ave/ano) }\end{array}$ \\
\hline 2006 & 15 & 1.914 .163 & 10.592 & 66,40 \\
2007 & 16 & 1.899 .133 & 10.556 & 66,70 \\
2008 & 17 & 2.218 .869 & 12.595 & 68,12 \\
2009 & 16 & 2.273 .228 & 13.050 & 68,89 \\
2010 & 16 & 2.391 .676 & 13.715 & 68,81 \\
2011 & 16 & 2.426 .271 & 15.035 & 74,36 \\
\hline
\end{tabular}




\begin{tabular}{lllll}
\hline 2012 & 16 & 2.592 .017 & 16.387 & 75,87 \\
2013 & 16 & 2.787 .388 & 16.897 & 72,74 \\
2014 & 16 & 2.969 .849 & 17.896 & 72,31 \\
2015 & 16 & 3.229 .408 & 20.443 & 75,96 \\
2016 & 17 & 4.142 .803 & 23.888 & 69,19 \\
2017 & 17 & 4.411 .496 & 26.109 & 71,02 \\
\hline
\end{tabular}

Fonte: Elaborado a partir de dados do IBGE, 2018.

A Tabela 5 apresenta a evolução da produção de ovos nas microrregiões do Estado do Pará entre os anos de 1995 a 2017. Observa-se que as microrregiões de Castanhal, Paragominas, Santarém e Belém, em conjunto, concentraram mais de $80 \%$ da produção estadual.

Pode-se observar, comparando o ano de 1995 e 2017, que é bem evidente a queda no percentual de produção da maioria das microrregiões paraenses, apenas Castanhal, Paragominas e Salgado exibiram crescimento da produção. A região de Paragominas apresentou um aumento significativo no decorrer dos anos, no qual obtinha o percentual de $2,47 \%$, em 1995 , atingindo $12,44 \%$, em 2017 . Isto se deve ao fato de os municípios de Paragominas, Dom Eliseu, Ulianópolis e Rondon do Pará, possuírem produção de grãos, sendo Paragominas o polo agrícola principal, onde tem se observado a experiência de bom desenvolvimento do agronegócio de grãos.

Com relação à representatividade da avicultura de postura da mesorregião metropolitana de Belém, no contexto estadual, destaca-se que está relacionada às características de tamanho e infraestrutura das granjas, melhor qualidade na nutrição e manejo sanitário, principalmente, nos municípios das microrregiões de Castanhal e Belém (Tabela 5).

TABELA 5 - Produção de ovos nas microrregiões do estado do Pará, 1995,2000, 2010, 2015 e 2017.

\begin{tabular}{|c|c|c|c|c|c|c|c|c|c|c|c|}
\hline Microrregião & & 1995 & (\%) & 2000 & (\%) & 2010 & (\%) & 2015 & (\%) & 2017 & (\%) \\
\hline Castanhal & & 7.997 & 24,34 & 2.716 & 11,06 & 10.051 & 41,19 & 17.079 & 53,09 & 19.963 & 54,60 \\
\hline Paragominas & & 810 & 2,47 & 1.15 & 4,68 & 3.795 & 15,55 & 4.436 & 13,79 & 4.549 & 12,44 \\
\hline Santarém & & 4.967 & 15,12 & 1.905 & 7,76 & 2.138 & 8,76 & 2.407 & 7,48 & 3.919 & 10,72 \\
\hline Belém & & 4.634 & 14,11 & 4.907 & 19,98 & 2.848 & 11,67 & 2.663 & 8,28 & 1.575 & 4,31 \\
\hline Salgado & & 502 & 1,53 & 710 & 2,89 & 1.071 & 4,39 & 1.192 & 3,71 & 1.069 & 2,92 \\
\hline Altamira & & 4.628 & 14,09 & 1.311 & 5,34 & 410 & 1,68 & 428 & 1,33 & 949 & 2,60 \\
\hline Bragantina & & 819 & 2,49 & 3.992 & 16,25 & 335 & 1,37 & 465 & 1,45 & 844 & 2,31 \\
\hline Guamá & & 1.987 & 6,05 & 1.66 & 6,76 & 735 & 3,01 & 544 & 1,69 & 547 & 1,50 \\
\hline Tomé-Açu & & 567 & 1,73 & 1.183 & 4,82 & 716 & 2,93 & 743 & 2,31 & 517 & 1,41 \\
\hline $\begin{array}{l}\text { Conceição } \\
\text { Araguaia }\end{array}$ & do & 616 & 1,88 & 505 & 2,06 & 268 & 1,10 & 239 & 0,74 & 418 & 1,14 \\
\hline $\begin{array}{l}\text { São Félix } \\
\text { Xingu }\end{array}$ & do & 345 & 1,05 & 654 & 2,66 & 337 & 1,38 & 383 & 1,19 & 372 & 1,02 \\
\hline Itaituba & & 605 & 1,84 & 353 & 1,44 & 238 & 0,98 & 282 & 0,88 & 326 & 0,89 \\
\hline Parauapebas & & 420 & 1,28 & 448 & 1,82 & 188 & 0,77 & 165 & 0,51 & 296 & 0,81 \\
\hline Tucuruí & & 601 & 1,83 & 678 & 2,76 & 174 & 0,71 & 229 & 0,71 & 256 & 0,70 \\
\hline Cametá & & 565 & 1,72 & 799 & 3,25 & 189 & 0,77 & 236 & 0,73 & 254 & 0,69 \\
\hline Redenção & & 1.384 & 4,21 & 600 & 2,44 & 251 & 1,03 & 246 & 0,76 & 222 & 0,61 \\
\hline
\end{tabular}




\begin{tabular}{lllllllllll}
\hline Marabá & 464 & 1,41 & 278 & 1,13 & 157 & 0,64 & 117 & 0,36 & 206 & 0,56 \\
Arari & 274 & 0,83 & 162 & 0,66 & 216 & 0,89 & 102 & 0,32 & 90 & 0,25 \\
Óbidos & 225 & 0,68 & 157 & 0,64 & 79 & 0,32 & 103 & 0,32 & 85 & 0,23 \\
Furos de Breves & 160 & 0,49 & 184 & 0,75 & 136 & 0,56 & 66 & 0,21 & 65 & 0,18 \\
Almeirim & 192 & 0,58 & 87 & 0,35 & 37 & 0,15 & 26 & 0,08 & 26 & 0,07 \\
Portel & 86 & 0,26 & 119 & 0,48 & 35 & 0,14 & 17 & 0,05 & 18 & 0,05 \\
\hline Pará & $\mathbf{3 2 . 8 4 9}$ & $\mathbf{1 0 0 , 0 0}$ & $\mathbf{2 4 . 5 5 9}$ & $\mathbf{1 0 0 , 0 0}$ & $\mathbf{2 4 . 4 0 4}$ & $\mathbf{1 0 0 , 0 0}$ & $\mathbf{3 2 . 1 6 8}$ & $\mathbf{1 0 0 , 0 0}$ & $\mathbf{3 6 . 5 6 4}$ & $\mathbf{1 0 0 , 0 0}$ \\
\hline
\end{tabular}

Fonte: Elaborado a partir de dados do IBGE, 2018.

\section{COMPORTAMENTO DOS PREÇOS}

No período analisado o preço recebido pelo produtor de ovos exibiu trajetórias diferenciadas ao longo dos anos. Entre 1995 e 1999 houve uma queda no preço dos ovos, sendo o ano de 1999 aquele que registrou o menor preço recebido pelo produtor, em torno de $\mathrm{R} \$ 3,00 /$ dúzia. Posteriormente, esse valor sofreu incremento expressivo durante os anos 2000 a 2002 (Figura 2).

Entre os anos de 2003 a 2008 o preço apresentou tendência de crescimento e, em 2009 , tem-se o maior preço recebido pelo produtor, cerca de $R \$ 6,00 /$ dúzia. Em termos mais gerais nota-se uma tendência de aumento, entre 1999 e 2009, sendo que a partir dai passam a ocorrer flutuações nessa variável, sugerindo maior instabilidade nos preços recebidos pelos avicultores.

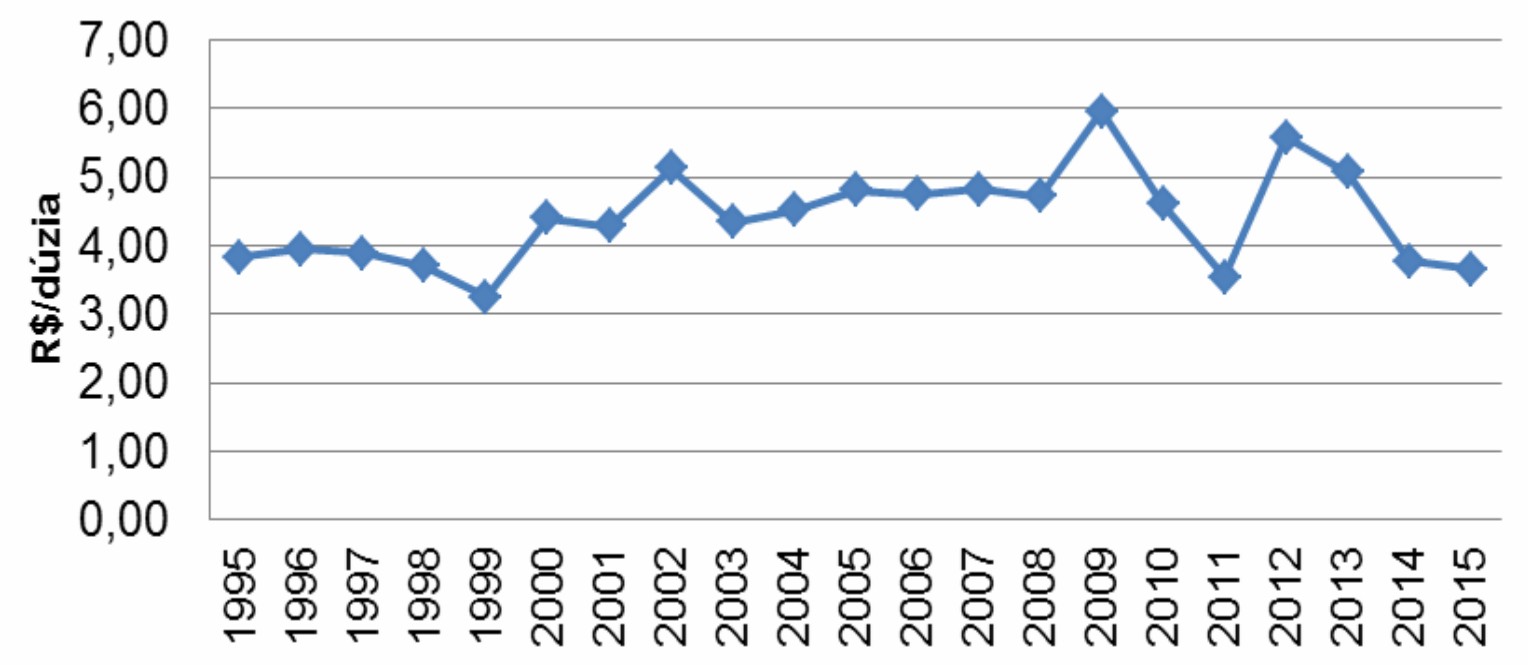

FIGURA 2 - Comportamento dos preços de ovos no Estado do Pará, 1995-2015. Nota: valores corrigidos para agosto de 2017 pelo IGP-DI (FGV, 2017).

Fonte: Elaborado a partir de dados do IBGE, (2017).

\section{CONCLUSÃO}

O estado do Pará é o segundo maior produtor de ovos de galinha da região Norte do Brasil. Apesar disso, a participação percentual da produção paraense em relação à produção nacional caiu, mesmo que ligeiramente, neste período.

As microrregiões de Santarém, Castanhal, Paragominas e Belém concentraram mais de $80 \%$ da produção estadual e são importantes zonas produtoras de ovos de galinhas. A região de Paragominas apresentou um crescimento significativo ao decorrer dos anos, devido a um bom desenvolvimento do agronegócio de grãos.

Os preços exibiram instabilidade no período analisado, com ligeira tendência 
de crescimento de 1999 a 2009, flutuações mais acentuadas entre 2009 e 2012, e tendência de queda a partir de 2013.

\section{REFERÊNCIAS}

BUENO, C. R. F.; GHOBRIL,C. N. Evolução da produção de ovos no estado de São Paulo nos últimos dez anos. Análises e Indicadores do Agronegócio, v. 12, n. 6, 2017. Disponível em:< http://www.iea.sp.gov.br/out/TerTexto.php?codTexto=14310 >. Acesso em 17 fev. 2018

CARNEIRO, $\mathrm{H}$. Metodologias para otimizar a variabilidade genética de núcleos de conservação de raças localmente adaptadas. 2012. 125 p. Tese (Doutorado em Ciências Animais) - Faculdade de Agronomia e Medicina Veterinária, Universidade de Brasília, Brasília, DF, 2012. Disponível em:< http://repositorio.unb.br/handle/10482/14245>. Acesso em: 17 fev. 2018.

CRUZ, F. G. G.; RUFINO, J.P. F.; MELO, R.D.; FEIJÓ, J. C.; DAMASCENO, J. L.; COSTA, A. P. G. Perfil socioeconômico da avicultura no setor primário do estado do Amazonas, Brasil. Revista em Agronegócio e Meio Ambiente, v.9, n.2, p.371-391, 2016.

Disponível em:<http://periodicos.unicesumar.edu.br/index.php/rama/article/view/4321>. Acesso em 10 out. 2018.

FAO. Food Agricultural Organization. Statistical - Database. Disponível em: <http://www.fao.org >. Acesso em: 21 out. 2018.

FUNDAÇÃO GETÚLIO VARGAS. FGVDADOS: Informação Econômica On-line. Disponível em: < http://fgvdados.fgv.br > Acesso em: 30 ago. 2017.

GUYONNET, V. Eggs and egg products: Consumers' attitudes, perceptions and behaviours. In: XXIV WORLD'S POULTRY CONGRESS. 2012. Salvador. Anais... Salvador, 2012. Disponível em: <http://www.facta.org.br/wpc2012cd/pdfs/plenary/Vincent_Guyonnet .pdf>. Acesso em: 06 ago. 2017.

IBGE. Pesquisa Pecuária Municipal. Disponível em:<https://sidra.ibge.gov.br/>. Acesso em: 21 out. 2018.

MARTINS, S. S. Situação e perspectivas da avicultura de postura. Informações Econômicas, v.32, n. 12, p. 48-52. 2002. Disponível em:< http://www.iea.sp.gov.br/out/verTexto.php?codTexto=1217>. Acesso em: 27 ago. 2018.

SANTOS M. A. S.; REBELLO F. K.; LOPES M. L. B. Análise de preços e margens de comercialização na avicultura de corte paraense. Belém: Banco da Amazônia (BASA), 2000. 31p. (Série Rural, 4). Disponível em:< https://www.researchgate.net/publication/303400911_Analise_de_precos_e_margen s_de_comercializacao_na_avicultura_de_corte_paraense>. Acesso em $1 \overline{7} \overline{\mathrm{fev}} .2018$. 